The following paper posted here is not the official IEEE published version. The final published version of this paper can be found in the Conference Record of the 2007 IEEE Industry Applications

Conference (42nd : 2007 : New Orleans, USA):pp.111-118

Copyright @ 2007 IEEE.

Personal use of this material is permitted. However, permission to reprint/republish this material for advertising or promotional purposes or for creating new collective works for resale or redistribution to servers or lists, or to reuse any copyrighted component of this work in other works must be obtained from the IEEE. 


\title{
Reducing Iron Loss in Interior PM Machines under Field-Weakening Conditions
}

\author{
W.L. Soong ${ }^{*}$, S.H. Han ${ }^{\#}$, T.M. Jahns ${ }^{\#}$ and N. Ertugrul ${ }^{*}$ \\ *University of Adelaide \\ Adelaide, Australia \\ "University of Wisconsin - Madison \\ Madison, WI, USA
}

\begin{abstract}
Field-weakening in interior PM machines is performed by using negative $d$-axis current to oppose the magnet flux and hence reduce the total fundamental $d$-axis flux at high speeds. Due to the rotor saliency, the $d$-axis current produces large amplitude harmonic airgap flux density components which can cause large harmonic stator iron losses. Reducing the magnet flux density reduces the required $d$-axis stator mmf to oppose it and hence reduces the field-weakening iron losses. However reducing the magnet flux density also reduces the magnet torque and hence increases the stator current requirement, particularly at lower speeds. This paper examines this trade-off for an automotive integrated starter/alternator using a graphical interior PM machine parameter plane approach.
\end{abstract}

Keywords: iron loss, field-weakening, interior PM machines

\section{INTRODUCTION AND OVERVIEW}

Interior permanent magnet (PM) machines offer wide constant power (field-weakening) speed ranges. Fieldweakening in these machines is performed by using a negative $d$-axis current $I_{d}$ in order to reduce the fundamental $d$-axis airgap flux density and hence flux-linkage. The characteristic current $I_{x}$ is the $d$-axis current required to reduce the fundamental $d$-axis stator flux-linkage at the terminals to zero. Under this "short-circuit" condition, ideally the $d$-axis fundamental airgap flux density would be zero but in practice there is still a significant fundamental airgap component due to finite stator leakage reactances.

To a first approximation iron losses are proportional to the square of the product of flux density and frequency. During field-weakening, the $d$-axis current is increased with increasing speed to reduce the $d$-axis airgap flux density such that the total machine flux varies inversely proportionally with speed and hence there is a constant terminal voltage. Under these conditions, the fundamental iron losses should ideally be constant and independent of speed. In fact, the iron losses during field-weakening would be expected to be lower than the open-circuit iron losses due to the lower $d$-axis airgap flux density. In practice, however, the iron losses under fieldweakening conditions are found to increase with speed and can be large [1]-[2]. In an example interior PM machine the fieldweakening iron losses were twice the open-circuit iron losses at the same speed [3].

The high field-weakening iron losses in interior PM machines is produced by high-amplitude, high-frequency harmonics in the $d$-axis armature reaction flux density waveform [3]. Consider a three-barrier interior PM machine with a smooth stator and sinusoidally-distributed stator airgap windings. Fig. 1 shows the spatial airgap flux density
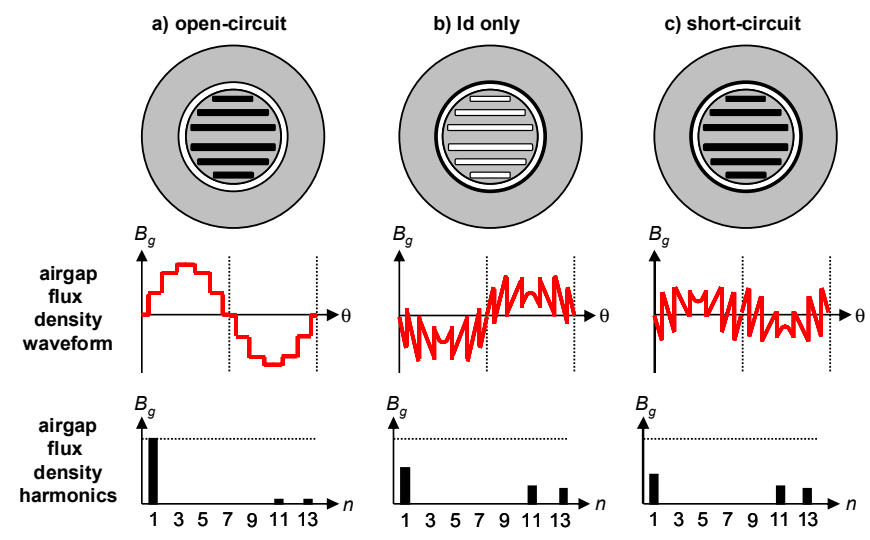

Fig. 1. Interior PM machine airgap flux density waveforms and harmonic content for (a) open-circuit, (b) $d$-axis current only and (c) short-circuit conditions.

waveforms and harmonics under three conditions: open-circuit, with only the PM rotor flux; $d$-axis current only, with $I_{d}=-I_{x}$ and no rotor magnets; and short-circuit, with both $I_{d}=-I_{x}$ and $\mathrm{PM}$ rotor flux. As the stator $\mathrm{mmf}$ is an ideal sinusoid, the only harmonics in the airgap flux density waveform are associated with the rotor barriers. These harmonics are relatively small with the PM flux but are large with the $d$-axis armature reaction flux. The $d$-axis armature reaction flux density harmonics in interior PM machines can produce substantial iron losses due to their high frequency and the harmonic losses can far exceed the fundamental losses. A key difference in surface PM machines is that the rotor is non-salient and hence the $d$-axis armature reaction is much more sinusoidal.

There are two main methods for reducing these iron losses. The first method is to optimise the motor geometry by carefully selecting the number of stator teeth and the rotor barrier thicknesses and angular locations, so that the harmonic airgap flux density components produced by the $d$-axis armature reaction do not "couple" with the stator teeth and yoke. Thus even though there may be large amplitude harmonic airgap flux density components, these do not result in large amplitude tooth and yoke flux density components. This method is discussed in detail in [4].

The second method to reduce iron losses, which is the focus of this paper, is to take a given motor geometry and optimise the magnet flux density and number of stator turns. In general, the smaller the magnet flux, the less $d$-axis armature reaction flux is required and hence the lower the harmonic iron losses. The disadvantage of reducing the magnet flux is that it will reduce the magnet torque. However, the output torque can be maintained by increasing the stator current. It is shown that the selection of the magnet flux density is a trade-off between the 
efficiency at high speeds on one hand, versus the efficiency at low speeds and the inverter current rating on the other.

The layout of this paper is as follows: in Section II it is shown that interior PM machines can be described by three dimensionless parameters which will be used later to define a parameter plane; Section III describes the requirements for an automotive integrated starter/alternator using which the iron loss minimization approach will be demonstrated; Section IV examines the stator current requirements to meet the above application using a parameter plane approach; and Section V presents the optimisation of an example machine design.

\section{INTERIOR PM MACHINE DIMENSIONLESS PARAMETERS}

Interior PM machines have three key equivalent circuit parameters : the (rms phase) magnet flux-linkage $\Psi_{m}$ and the $d$ and $q$-axis stator inductances $L_{d}$ and $L_{q}$. In this section it is shown that these can be replaced by three dimensionless parameters. It is based on extending the analysis method described in [5] for surface PM machines to interior PM machines. The effect of stator resistance, iron loss, and magnetic saturation is neglected.

The $q$-axis voltage $V_{q}$ and $d$-axis voltage $V_{d}$ equations are,

$$
\begin{gathered}
V_{q}=\omega_{e} \Psi_{m}+\omega_{e} L_{d} I_{d} \\
V_{d}=-\omega_{e} L_{q} I_{q}
\end{gathered}
$$

where $\omega_{e}$ is the electrical frequency and $I_{d}$ and $I_{q}$ are the $d$ - and $q$-axis current components respectively. The stator voltage $V$ and current $I$ are defined by,

$$
\begin{gathered}
V=\sqrt{V_{d}^{2}+V_{q}^{2}} \\
I=\sqrt{I_{d}^{2}+I_{q}^{2}}
\end{gathered}
$$

The following three machine parameters which define an interior PM machine design were chosen: the saliency ratio $\xi$,

$$
\xi=L_{q} / L_{d}
$$

the characteristic current $I_{x}$,

$$
I_{x}=\Psi_{m} / L_{d}
$$

and the peak line open-circuit voltage at maximum speed, henceforth referred to as the peak back-emf $E_{p}$,

$$
E_{p}=\sqrt{6} \omega_{e m} \Psi_{m}
$$

where $\omega_{e m}$ is the electrical frequency at the maximum operating speed.

The physical significance of the last two parameters are that at the maximum speed, the characteristic current is the shortcircuit output current and the peak back-emf is the peak generated open-circuit rectified output voltage.

The voltage equations (1) and (2) can be expressed in terms of the three design parameters (5)-(7) as,

$$
\begin{aligned}
& V_{q}=\frac{\omega_{e}}{\omega_{e m}} \frac{E_{p}}{\sqrt{6}}\left(1+\frac{I_{d}}{I_{x}}\right) \\
& V_{d}=\frac{\omega_{e}}{\omega_{e m}} \frac{E_{p}}{\sqrt{6}}\left(-\frac{\xi I_{q}}{I_{x}}\right)
\end{aligned}
$$

The output power $P$ can be expressed in terms of the three design parameters using (8) and (9) as,

$$
P=m\left(V_{q} I_{q}+V_{d} I_{d}\right)=\frac{\omega_{e}}{\omega_{e m}} \frac{m E_{p}}{\sqrt{6}} I_{q}\left(1+(1-\xi) \frac{I_{d}}{I_{x}}\right)
$$

where $m$ is the number of phases. In (8) to (10), if the speed is defined as a fraction of maximum speed, then the equations are independent of the number of poles.

The maximum allowable machine rms phase voltage $V_{o}$ is set by the dc link voltage $V_{d c}$, where assuming linear modulation it is given by,

$$
V_{o}=\frac{V_{d c}}{\sqrt{6}}
$$

For a given dc link voltage it is possible to achieve higher phase voltages using overmodulation. However, in practice it is also desirable to have some voltage margin to allow effective current control at high speeds.

The minimum possible machine current to meet the maximum output power rating $P_{o}$ occurs when the machine is operating at rated voltage, with unity power-factor and $100 \%$ efficiency. In this paper this value of current will be referred to as the natural current $I_{n}$ and is given by,

$$
I_{n}=\frac{P_{o}}{m V_{o}}
$$

The natural current forms a convenient benchmark for comparison purposes. The stator current is normalized against the natural current and the peak back-emf $E_{p}$ is normalized against the peak rated voltage $\sqrt{6} V_{o}$. This results in three dimensionless interior PM machine parameters: the saliency ratio $\xi$, the normalized peak back-emf $E_{p} /\left(\sqrt{ } 6 V_{o}\right)$, and the normalized characteristic current $\left(I_{x} / I_{n}\right)$.

\section{AN APPLICATION OF IRON LOSS MiNIMIZATION : INTEGRATED STARTER-ALTERNATOR}

The proposed iron loss minimization approach is based on defining a parameter plane using the three dimensionless parameters for an interior PM machine described above. To illustrate the approach it will be applied to an automotive integrated starter-alternator (ISA). This application requires an extremely wide generating constant power speed range (CPSR). An example ISA specification is given in [6] and is illustrated in Fig. 2 assuming an offset-coupled design with a belt ratio of $3: 1$ between the engine and ISA. In generating mode, the specification is an output power of $4 \mathrm{~kW}$ at 1,800 $\mathrm{r} / \mathrm{min}$ increasing linearly to $6 \mathrm{~kW}$ at the maximum speed of 18 $\mathrm{kr} / \mathrm{min}$ which corresponds to a CPSR of 10:1. In motoring mode, a peak starting torque of $50 \mathrm{Nm}$ is required at low speeds. This is roughly 2.5 times the generating torque at minimum speed (1800 r/min).

Two interior PM machines were previously designed for this ISA application, including an offset-coupled design and a direct-drive design. Fig. 3 shows cross-sections of one pole of each design and TABLE I. shows a comparison of their parameters.

Design A is a four-pole offset-coupled machine [7] which is based on a commercial induction motor stator and has a three- 


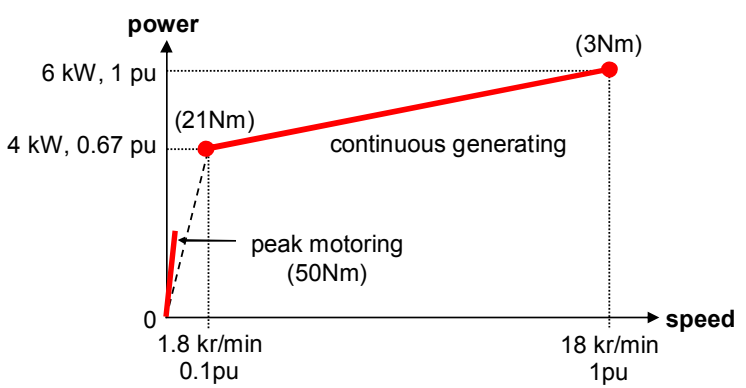

Fig. 2. Automotive integrated starter-alternator generating and motoring specifications assuming a 3:1 belt ratio between the alternator and engine.
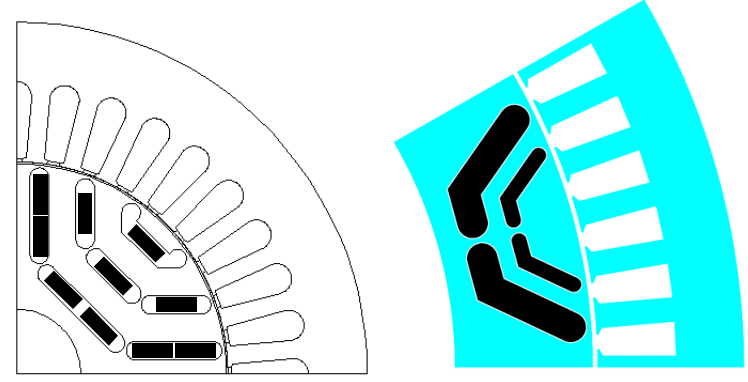

Fig. 3. Cross-section of one pole of the four-pole offset-coupled design A (left) [7] and twelve-pole direct-drive design C (right) [6].

TABLE I. COMPARISON OF PARAMETERS FOR DIRECT DRIVE AND OFFSET-COUPLED INTERIOR PM ISA DESIGNS. THE PERFORMANCE FOR DESIGN A IS MEASURED [7], DESIGN B IS CALCULATED FROM LINEAR PARAMETERS, AND DESIGN C IS CALCULATED FROM FE ANALYSIS [6].

\begin{tabular}{|l|c|c|c|}
\hline & Design A & Design B & Design C \\
\hline Parameter & $\begin{array}{c}\text { Offset- } \\
\text { Coupled } \\
\text { [7] }\end{array}$ & $\begin{array}{c}\text { Modified } \\
\text { Offset } \\
\text { Coupled }\end{array}$ & $\begin{array}{c}\text { Direct- } \\
\text { Drive } \\
{[6]}\end{array}$ \\
\hline Gear Ratio & $3: 1$ & $3: 1$ & $1: 1$ \\
\hline Poles & 4 & 4 & 12 \\
\hline Stator Outer Diameter & $153 \mathrm{~mm}$ & $153 \mathrm{~mm}$ & $272 \mathrm{~mm}$ \\
\hline Stack Length & $95 \mathrm{~mm}$ & $95 \mathrm{~mm}$ & $60 \mathrm{~mm}$ \\
\hline Magnet Remanence $B_{r}$ & $1.05 \mathrm{~T}$ & $1.05 \mathrm{~T}$ & $0.28 \mathrm{~T}$ \\
\hline Rated Phase Voltage Vrms & $240 \mathrm{~V}$ & $240 \mathrm{~V}$ & $19.3 \mathrm{~V}$ \\
\hline Natural Current $I_{n}$ & $8.33 \mathrm{~A}$ & $8.33 \mathrm{~A}$ & $104 \mathrm{~A}$ \\
\hline Saliency Ratio $($ sat'd) $\xi$ & 2.7 & 2.7 & 3.3 \\
\hline Characteristic Current $I_{x}$ & $9.3 \mathrm{~A}$ & $9.3 \mathrm{~A}$ & $97 \mathrm{~A}$ \\
\hline Max. Generating Current & $9.3 \mathrm{~A}$ & $13 \mathrm{~A}$ & $224 \mathrm{~A}$ \\
\hline Max. Motoring Current & $12 \mathrm{~A}$ & $22 \mathrm{~A}$ & $327 \mathrm{~A}$ \\
\hline Peak Back-EMF & $7.82 \mathrm{pu}$ & $1.96 \mathrm{pu}$ & $1.24 \mathrm{pu}$ \\
\hline Characteristic Current $I_{x}$ & $1.11 \mathrm{pu}$ & $1.11 \mathrm{pu}$ & $0.94 \mathrm{pu}$ \\
\hline Max. Generating Current & $1.11 \mathrm{pu}$ & $1.58 \mathrm{pu}$ & $2.16 \mathrm{pu}$ \\
\hline Max. Motoring Current & $1.44 \mathrm{pu}$ & $2.61 \mathrm{pu}$ & $3.16 \mathrm{pu}$ \\
\hline
\end{tabular}

barrier interior PM machine rotor containing rare-earth magnets. The measured parameters and performance for Design A are given in TABLE I. The saliency ratio shown is the saturated saliency ratio consistent with delivering rated motoring output torque. The unsaturated saliency ratio approaches 6.

Design A has a large peak back-emf of nearly 8 pu. That is, the open-circuit output voltage at maximum speed is eight times rated voltage. It was found to have an extremely high iron loss which was measured at approx. $900 \mathrm{~W}$ at one-third of maximum speed [3]. Assuming this varies with the square of speed, this would produce an estimated $8.1 \mathrm{~kW}$ iron loss at maximum speed compared to the $6 \mathrm{~kW}$ output power.

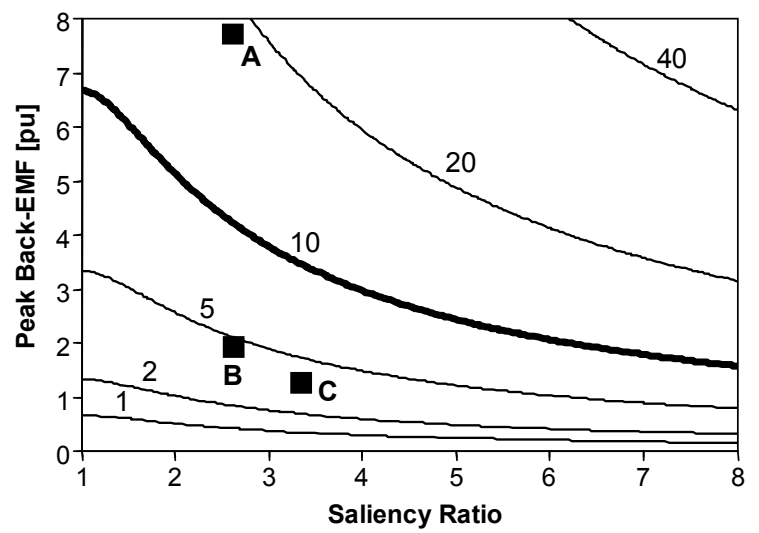

Fig. 4. Contour plot of calculated constant power speed range on the axes of peak back-emf and saliency ratio for machine designs where the rated, characteristic and natural currents are equal [7]. The location of the three designs are shown.

To illustrate the design tradeoffs, Design $\mathrm{B}$ is a fictitious modified version of Design A with the same stator and rotor geometry but half the magnet remanent flux and half the number of turns. As will be shown in Section V, Design B has the same characteristic current but one quarter of the peak back-emf (approx. 2 pu) of Design A. Its calculated performance assuming constant parameters is shown in TABLE I.

Design $C$ is a direct-drive machine [6] designed for the same ISA specification. The machine has roughly twice the diameter of the offset-coupled design and two-thirds of the stack length. It is based on a twelve-pole, two-barrier rotor design which uses ferrite magnets and relies heavily on reluctance torque. Finite-element analysis was used to calculate the machine parameters and performance shown in TABLE I. The saliency shown in the table reflects the saturated saliency when delivering rated motoring torque. The machine has a low peak back-emf of approx. $1.2 \mathrm{pu}$.

The offset-coupled and the direct-drive machines have different rated voltages, but valid comparisons can be obtained by using normalised parameters. The machines all have characteristic currents which are in the vicinity of $1 \mathrm{pu}$, meaning that they are close to the natural current value from (12), and saturated saliency ratios of approximately three.

A simple design rule in field-weakening applications is to make the rated and characteristic currents equal to each other and as close to the natural current as possible. Using this rule, the contour plot of constant power speed range (CPSR) as a function of saliency ratio and peak back-emf can be derived [7] leading to the results shown in Fig. 4. In this case the minimum speed in the CPSR range is defined as the speed when the output power equals $2 / 3$ of the maximum power. With this definition, a CPSR of 10 is required to meet the ISA specification in Fig. 2.

Fig. 4 shows that, for a surface PM machine $(\xi=1)$, the peak back-emf must be nearly 7 pu to limit the generating current to values less than or equal to the natural current over the entire speed range. The required peak back-emf to achieve the CSPR of 10 falls with increasing saliency ratio but is still approx. $4 \mathrm{pu}$ with a saliency ratio of 3 . In practice, this is a very conservative requirement. As will be seen later, if a somewhat 

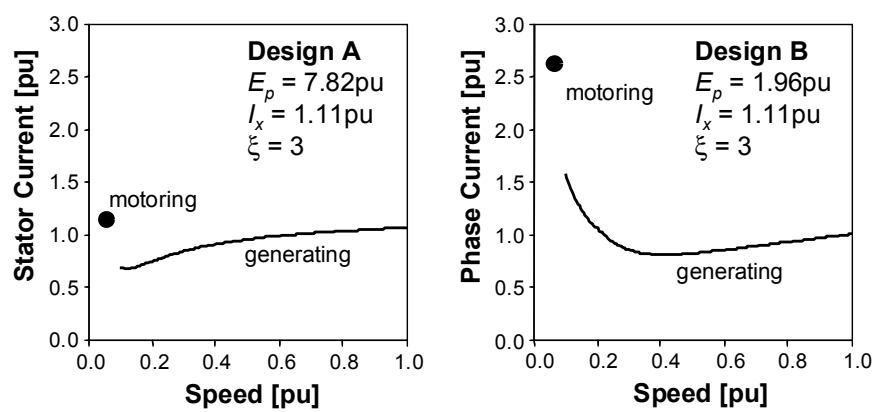

Fig. 5. Calculated stator current versus speed for generating (line) and motoring (circle) for the original (A) and modified (B) offset-coupled interior PM machines using constant parameters.

larger stator current at low speeds is allowable, then the peak back-emf for a given saliency ratio can be much lower.

Fig. 4 shows that with the assumption of a rated current equaling the characteristic and natural currents, the high peak back-emf, offset-coupled design (A) has a generating CPSR approaching 20:1, while the CPSR of the modified offsetcoupled design (B) and the direct-drive design (C) are in the range $3: 1$ to $5: 1$. The latter two designs can still meet the 10:1 CPSR specification, but will require a higher generating stator current than the natural current at low speeds.

\section{INTERIOR PM MACHINE STATOR CURRENT}

This section examines the influence of the selection of the three dimensionless parameters on the required stator current of an interior PM machine design under both generating and motoring conditions when meeting the ISA specification.

For a given value of peak back-emf, characteristic current, and saliency ratio, the minimum stator current to meet the power requirement at a particular speed can be determined by numerically finding the values of $I_{d}$ and $I_{q}$ that yield the lowest current (4) while satisfying both the required output power (10) and the terminal voltage requirement (3), (8) and (9). Fig. 5 shows the calculated stator current versus speed to meet the generating and motoring power requirement for the original (A) and modified (B) offset-coupled interior PM machine designs where the saturated saliency ratio is approximated as three.

The effect of varying the peak back-emf and characteristic current on the required stator current ratings can be illustrated using the interior PM machine parameter plane. This plane has an $x$-axis corresponding to the normalized characteristic current $I_{x}$ and the $y$-axis corresponding to the normalized peak backemf voltage. The results are calculated using a constant saliency ratio $\xi$ of 3 which is consistent with the saturated value for the direct-drive and offset-coupled designs.

Fig. 6 shows a contour plot of the normalized generating stator current at maximum speed to meet the $6 \mathrm{~kW}$ output power requirement. The stator current must always exceed the natural current $1 \mathrm{pu}$. For higher values of peak back-emf it is not possible to achieve the desired output power if the characteristic current is less than $1 \mathrm{pu}$ (the natural current). In this region, the minimum stator current occurs with characteristic current values of $1 \mathrm{pu}$; increasing the characteristic current increases the stator current. For low values of peak back-emf, operation is possible with values of

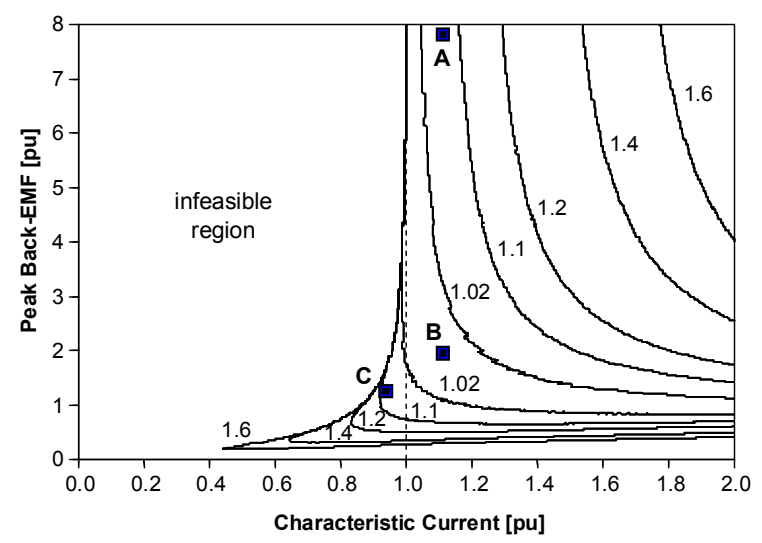

Fig. 6. Stator current at maximum speed for $6 \mathrm{~kW}$ generating power. Contour plot of normalised stator current on interior PM parameter plane for saliency ratio $\xi=3$. It shows the location of three machine designs and also a dashed line showing the characteristic current equal to the natural current.

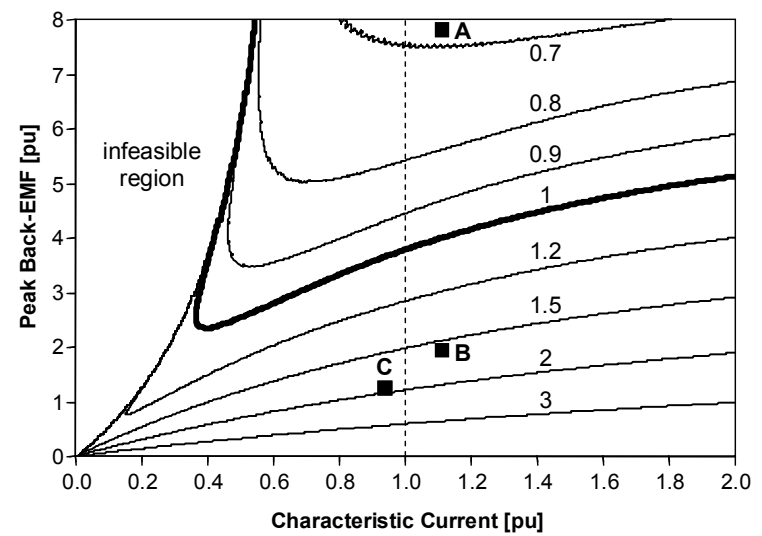

Fig. 7. Stator current at minimum generating speed for $4 \mathrm{~kW}$ generating power. Contour plot of normalised stator current on interior PM parameter plane for saliency ratio of $\xi=3$.

characteristic current less than $1 \mathrm{pu}$, but this requires higher stator currents. The figure shows it is best to keep the characteristic current slightly larger than the natural current, (say $1.1 \mathrm{pu}$ ) in order to minimize the stator current at maximum speed while keeping some margin for design tolerances.

Fig. 6 (and the following figures) also show the locations (squares) of the three machine designs in TABLE I. The original (A) and modified (B) offset-coupled designs have characteristic currents of approx $1.1 \mathrm{pu}$ while the direct-drive design (C) has a characteristic current of $0.94 \mathrm{pu}$.

Fig. 7 shows the normalized generating stator current at minimum generating speed. The infeasible region is much smaller than for maximum speed in the previous figure. In this case, the stator current required to meet the $4 \mathrm{~kW}$ requirement is roughly inversely proportional to the peak back-emf. A value of $E_{p}$ greater than approx. $4 \mathrm{pu}$ is required to hold the stator current less than $1 \mathrm{pu}$ for a value of $I_{x}=1 \mathrm{pu}$, which is consistent with the value predicted by Fig. 4 for a saliency ratio of 3. The figure shows that using lower values of peak backemf substantially increases the required generating current at minimum speed to values of 1.5 to 2 pu for designs $B$ and $C$, while design A with its high peak back-emf has a value of less than $0.7 \mathrm{pu}$. 


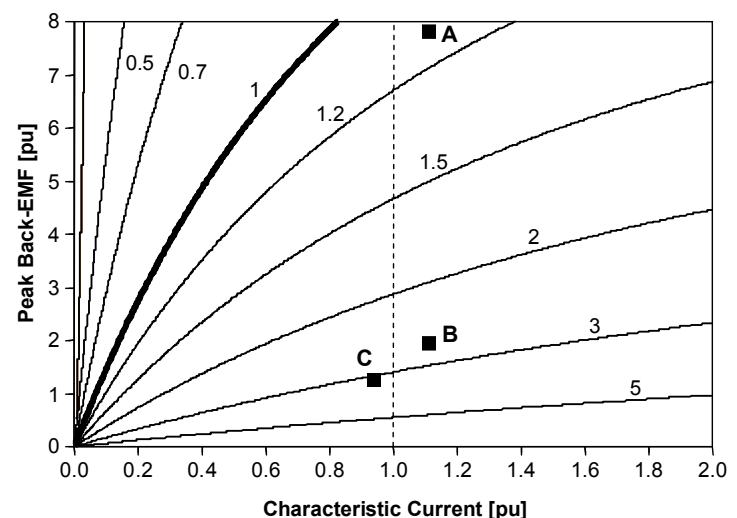

Fig. 8. Stator current in motoring. Contour plot in interior PM parameter plane for saliency ratio of $\xi=3$.

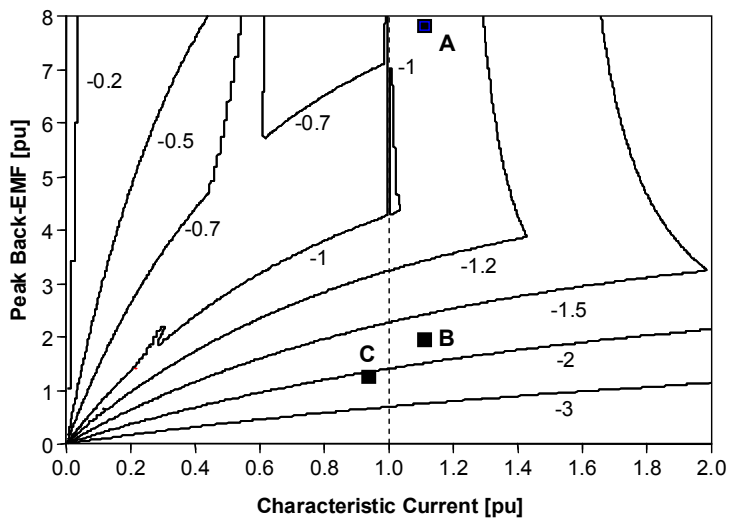

Fig. 9. Worst-case negative $d$-axis current during motoring or generating.

Contour plot in interior PM parameter plane for saliency ratio of $\xi=3$.

Fig. 8 shows the normalised motoring stator current to meet the $50 \mathrm{Nm}$ peak starting torque requirement. Note there is no infeasible region as the starting torque requirement can always be met with sufficient current. For the original offset-coupled design $\mathrm{A}$, the required current is close to the natural current, but the stator current increases rapidly to approximately $3 \mathrm{pu}$ as the peak back-emf is reduced for designs B and C. This is consistent with the results in TABLE I.

In addition, demagnetisation is an important consideration in PM machines. Fig. 9 shows the largest negative $d$-axis current that is required under either generating or motoring conditions. The abrupt changes in the contours at values of peak back-emf of approx. $6 \mathrm{pu}$ and characteristic currents of approx. $0.5 \mathrm{pu}$ arises from combining the maximum $d$-axis component of the stator currents shown in Fig. 7 and Fig. 8. For design A the maximum negative $d$-axis current is limited to about $-1.1 \mathrm{pu}$ while for designs $\mathrm{B}$ and $\mathrm{C}$ it can approach $-2 \mathrm{pu}$.

The demagnetisation factor is the ratio of the largest $d$-axis current to the characteristic current and is plotted in Fig. 10. Neglecting stator leakage inductance, a demagnetisation factor of 1 would imply zero fundamental airgap flux. Ideally, the demagnetisation factor should be less than 1. However, for high-saliency designs, the relatively large stator leakage inductance means that significantly larger values may be acceptable. The demagnetisation factors of approx. 1.5 and 2 for the designs B and C, respectively, require finite-element analysis to determine if they are at risk of demagnetisation.

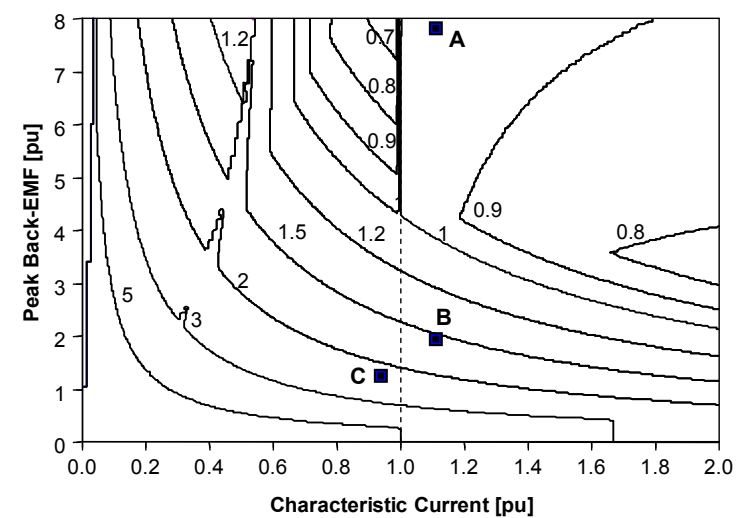

Fig. 10. Worst-case demagnetization factor. Contour plot in interior PM parameter plane for saliency ratio of $\xi=3$.
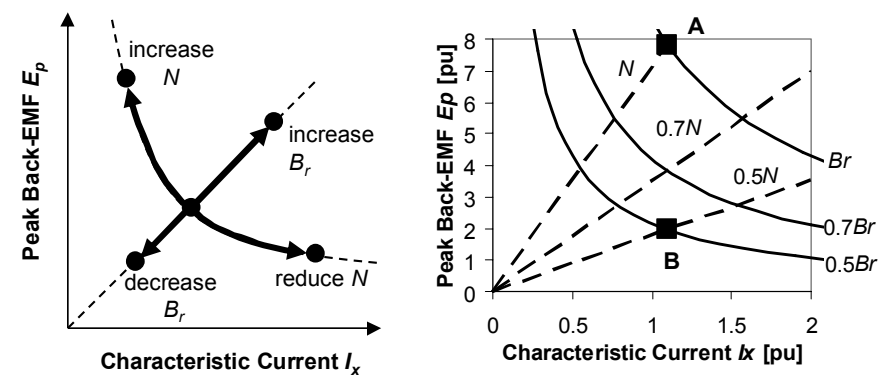

Fig. 11. Effect of changing the magnet remanent flux density $B_{r}$ and the number of turns $N$ on the location of design A in the parameter plane.

This section has shown that a good choice of characteristic current for this application is $1.1 \mathrm{pu}$, and that reducing the peak back-emf causes the stator currents to increase significantly.

\section{MACHINE EFFICIENCY OptimisATION}

Consider a machine with a particular stator and rotor geometry and, hence, saliency ratio. It is interesting to examine how the machine's location in the parameter plane can be altered by changing its magnet remanent flux density and the number of stator turns. In this analysis, the effect of magnet leakage is neglected, although this can be taken into account by instead considering the magnet-induced airgap flux density. It is important to note that saturation is also neglected.

For example, changing the magnet remanent flux density $B_{r}$ changes both the peak back-emf and the characteristic current proportionally, hence the design moves along a straight line passing through the origin (see Fig. 11). On the other hand, increasing the number of turns in the winding $N$ increases the peak back-emf while reducing the characteristic current proportionally, resulting in the design moving in a hyperbola in the parameter plane. Fig. 11 (right) shows how the location of the offset-coupled machine can be moved for its original location (A) to the new location (B) by halving both the number of turns and remanent flux density. Design $B$ has the same characteristic current as design A, but one quarter of the peak back-emf (see TABLE I. ).

As shown in Fig. 6 to Fig. 8, the location of the design in the parameter plane affects both the generating and motoring current ratings. Therefore, the effect of the parameter plane location on the stator copper and iron losses and, hence, efficiency needs to be investigated. 


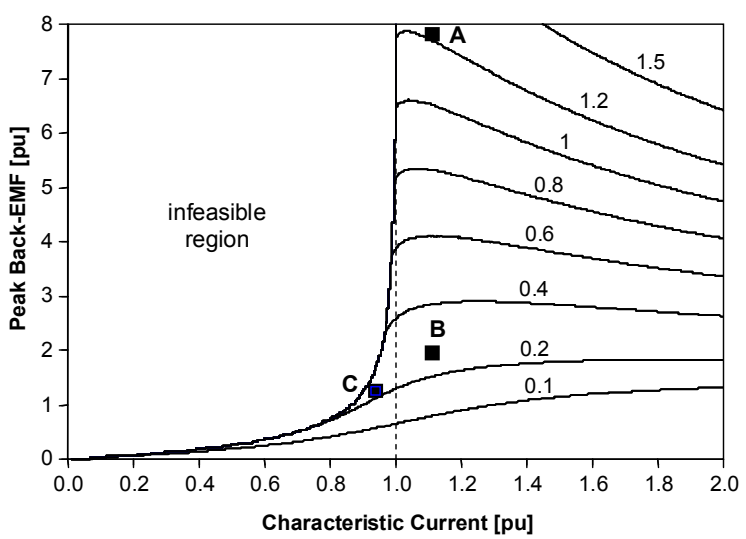

Fig. 12. Normalised iron losses at max. generating speed for offset-coupled machine. Contour plot in interior PM parameter plane for $\xi=3$. Actually a plot of the square of the $d$-axis stator mmf at maximum speed normalised to give the estimated iron loss for design $\mathrm{A}$.

\section{A. Losses at Maximum Generating Speed}

During field-weakening, the stator iron loss is roughly proportional to the square of the $d$-axis stator mmf due to the large-amplitude harmonic $d$-axis armature reaction flux components. The $d$-axis stator mmf is given by the product of the number of turns (see Fig. 11) and the $d$-axis current. At the maximum generating speed, the $d$-axis stator current is found to be comparable to the total stator current in Fig. 6 except for minor differences for $E_{p}<0.5 \mathrm{pu}$.

The original offset-coupled machine (A) has a measured iron loss of about $900 \mathrm{~W}$ at one-third of maximum speed. Assuming that this loss varies with the square of the product of frequency and $d$-axis mmf yields the iron loss results shown in Fig. 12 normalized to the $6 \mathrm{~kW}$ rated power. This clearly illustrates that design A has extremely large iron losses which were estimated to be comparable to the output power at maximum speed. Reducing the peak back-emf of design A reduces the $d$-axis stator current slightly (see Fig. 6) but, more importantly, reduces the number of turns (see Fig. 11) and results in a substantial reduction of the stator $d$-axis mmf and, hence, iron loss. It should be noted that the iron loss results shown in Fig. 12 are only applicable to the particular machine geometry and lamination material used in designs A and B. As a result, this figure cannot be used to estimate the iron losses for design $\mathrm{C}$ which has a completely different geometry.

The stator copper $I^{2} R$ loss is affected by both the stator current $I$ and the stator resistance $R$. Assuming a constant copper slot fill factor, the stator resistance is proportional to the square of the number of turns $N^{2}$. Thus, the stator copper losses are proportional to the square of the stator mmf which is similar to the iron losses. The normalized copper loss of the offset-coupled machine at maximum generating speed is shown in Fig. 13. Not surprising, the copper loss curves are very similar in shape to the iron losses in Fig. 12 but roughly an order of magnitude smaller.

From the results in Fig. 12 and Fig. 13, the predicted efficiency can be plotted in Fig. 14. This figure shows that significant improvements in the high-speed generating efficiency can be obtained by reducing the peak back-emf. Although the numerical values in Fig. 12 to Fig. 14 are only valid for the particular magnetic design of the offset-coupled

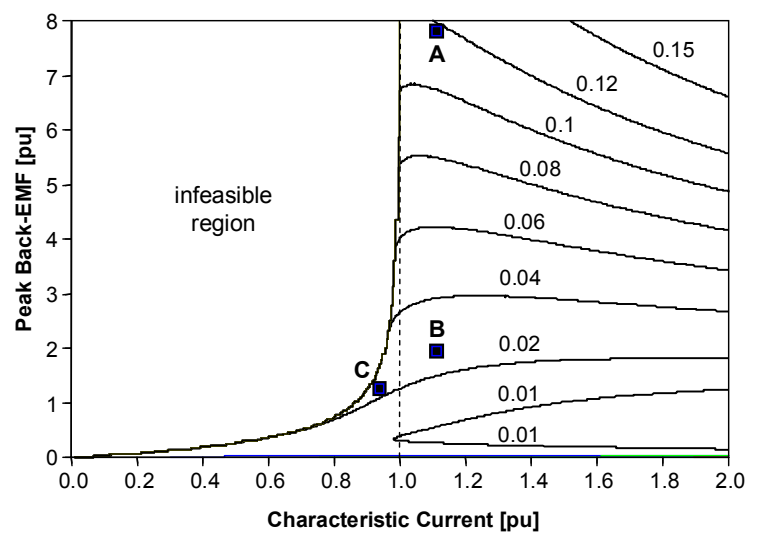

Fig. 13. Normalised copper losses at max. generating speed for offset-coupled machine. Contour plot in interior PM parameter plane for $\xi=3$.

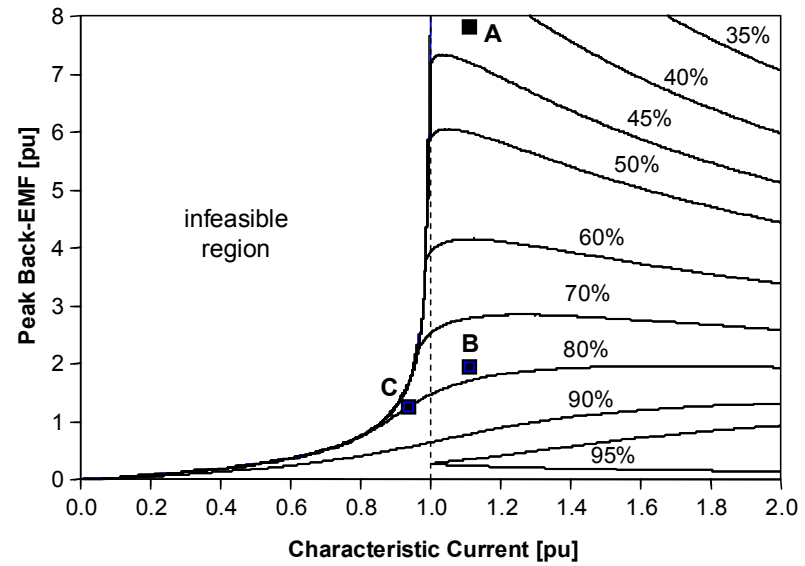

Fig. 14. Efficiency at max. generating speed for offset-coupled machine. Contour plot in interior PM parameter plane for saliency ratio of $\xi=3$.

machine, they show the general trend of increasing efficiency with reduced peak back-emf.

\section{B. Losses at Minimum Generating Speed}

This subsection explores the effect of changing the number of turns and magnet remanent flux density on the performance at the minimum generating speed. At this speed, the machine may not be subject to field weakening, so the iron losses are likely to be closer to the open-circuit losses than the shortcircuit losses. Thus, the iron losses were roughly approximated as being proportional to the square of the magnet remanent flux density instead of the square of the stator mmf (see Fig. 15). Since this speed is one-tenth of the maximum speed, the iron losses should be roughly one hundred times smaller as confirmed by comparing Fig. 15 with Fig. 12.

The copper losses are still proportional to the square of the stator mmf. Hence, Fig. 16 shows variations due to both the stator current in Fig. 7 and the number of turns in Fig. 11.

The predicted efficiency at the minimum generating speed for the offset-coupled machine is shown in Fig. 17. The efficiency is much higher than that at the maximum generating speed due to the very high iron losses in this machine.

\section{New Design with Reduced Iron Loss}

In Section I of this paper, a means for reducing iron loss based on the optimizing the design of the stator and rotor 


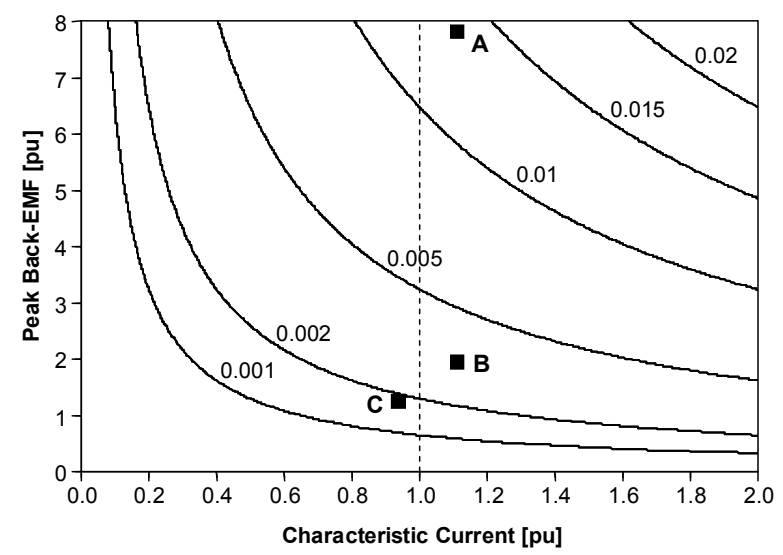

Fig. 15. Predicted iron losses at min. generating speed for offset-coupled machine. Contour plot in parameter plane for saliency ratio of $\xi=3$.

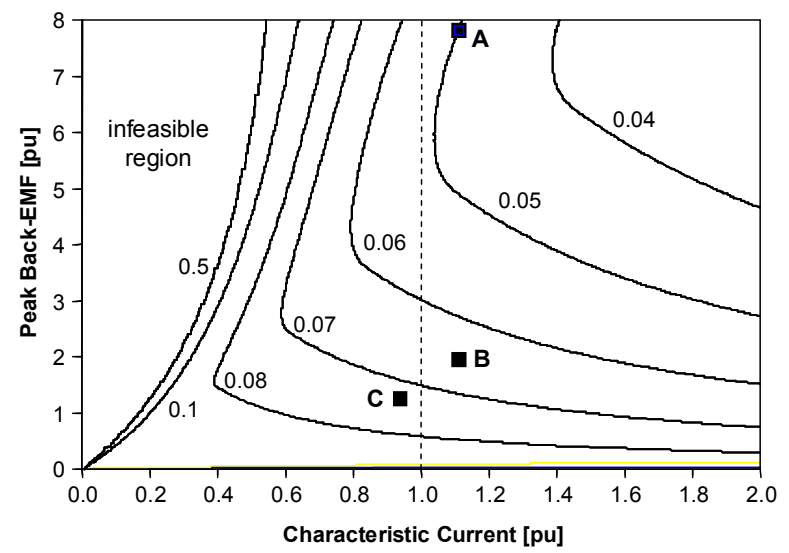

Fig. 16. Predicted copper losses at min. generating speed for offset-coupled machine. Contour plot in parameter plane for saliency ratio of $\xi=3$.

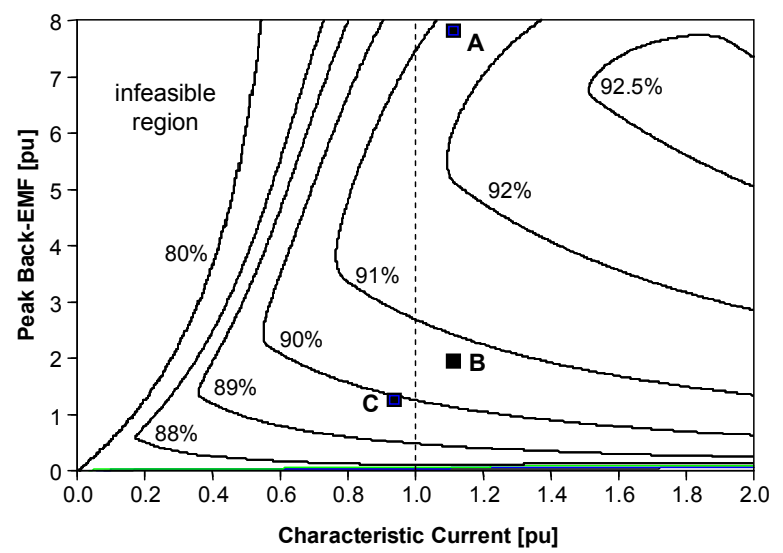

Fig. 17. Predicted efficiency at min. generating speed for offset-coupled machine. Contour plot in parameter plane for saliency ratio of $\xi=3$.

magnetic geometry was discussed. This has been implemented in [4] and required two steps. Firstly, the angular location and thickness of the three rotor barriers were modified to produce a more sinusoidal rotor $\mathrm{mmf}$ shape in which the major harmonics were increased in frequency from harmonic numbers of $12 \pm 1$ to $18 \pm 1$. Secondly, the number of stator teeth was reduced from 36 to 24 . With the lower number of stator teeth and the higher-frequency airgap harmonics, the coupling between the airgap harmonics and the stator teeth and yoke was reduced, leading to a substantial reduction of the iron losses.

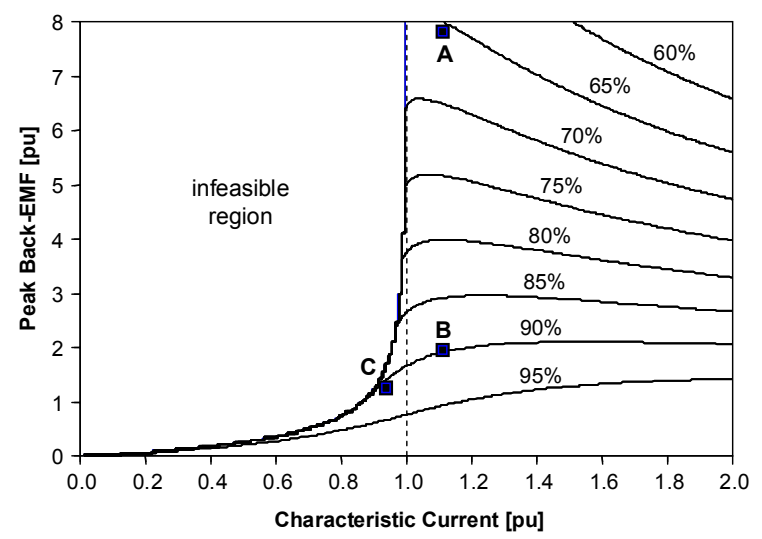

Fig. 18. Predicted efficiency at max. generating speed for offset-coupled machine with reduced iron loss. Contour plot in parameter plane for $\xi=3$.

With the above approach, finite-element analysis showed that the iron loss could be reduced by a factor of approx. three while keeping the same values of peak back-emf and characteristic current [4]. Assuming that this degree of improvement can be achieved in this application substantially improves the predicted efficiency at maximum speed as shown in Fig. 18 compared to Fig. 14. Design A improves from $42 \%$ to $65 \%$ and design B improves from approx. $80 \%$ to approx. $90 \%$.

The effect of this rotor design technique on the efficiency at the minimum generating speed is significantly smaller since the efficiency is dominated by copper loss at this lower speed.

\section{Optimisation Summary}

Fig. 19 shows the variation of the stator current (top) and efficiency (bottom) with peak back-emf for the offset-coupled machine designs with both the original and improved iron loss stator and rotor magnetic designs. A characteristic current of $1.1 \mathrm{pu}$ was assumed. The stator current graph is based on Fig. 6, Fig. 7, and Fig. 8. It shows that reducing the peak back-emf increases the required stator current at all speeds. This has the greatest effect on the motoring current followed by the current at the minimum generating speed, with the current at the maximum generating speed being relatively insensitive to peak back-emf until it drops below 1 pu. The graph shows vertical lines corresponding to designs $\mathrm{A}$ and $\mathrm{B}$. It is shown that the current ratings of design B are substantially larger than design A. Only one set of stator current curves are shown as the stator current calculation neglects copper and iron losses.

Fig. 19 also shows predicted efficiency curves under generating conditions at minimum speed (solid lines) and maximum speed (dashed lines) for both the original and improved iron loss rotor magnetic designs. It is based on Fig. 14, Fig. 17 and Fig. 18. Firstly considering the original design, it shows that, with the high iron losses, substantial efficiency improvements at maximum speed can be obtained by reducing the peak back-emf with only a modest penalty in the efficiency at minimum generating speed. Secondly, the low iron loss magnetic design produces a substantial improvement in efficiency at maximum speed, but only a small improvement at minimum speed since the copper losses are dominant in this region. The minimum generating efficiency of design $\mathrm{B}$ with the low iron loss magnetic design is approx. $90 \%$ compared to $40 \%$ for design A with the original magnetic design. 

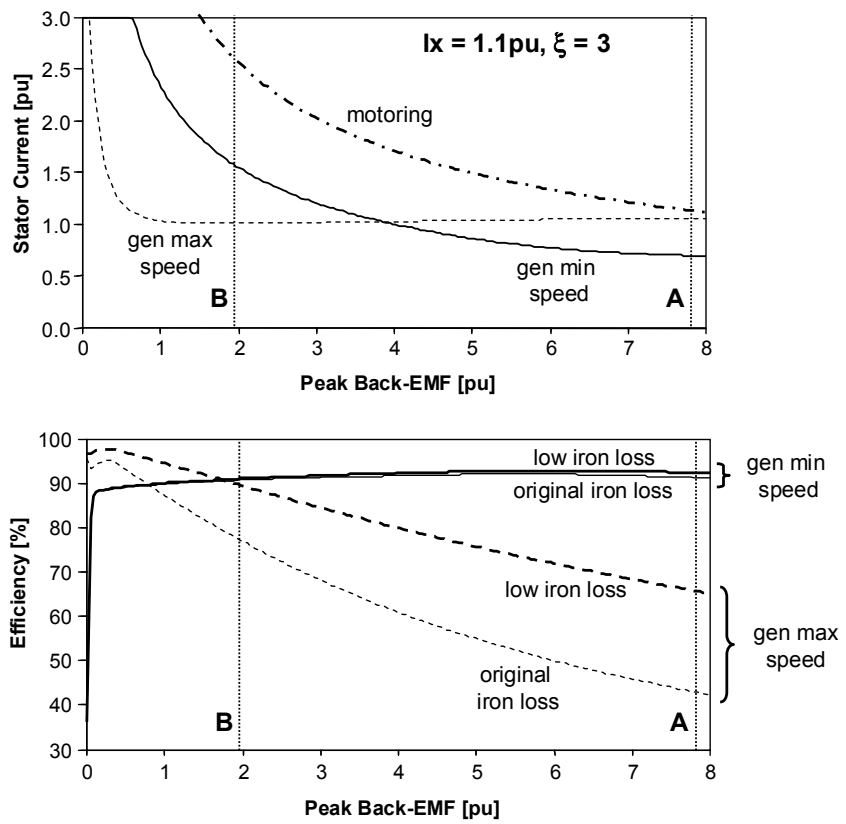

Fig. 19. Variation of stator current (top) and efficiency (bottom) with peak back-emf for the offset-coupled machine designs A and B. The stator current graph shows curves for the motoring current, and the generating currents at maximum and minimum speed. The efficiency graph shows the efficiency at minimum and maximum speed for the original iron loss and the low iron loss

designs. A value of characteristic current of 1.1 pu and saliency of 3 was

assumed and vertical lines are used to show the locations of designs A and $\mathrm{B}$.

The selection of peak back-emf is thus a trade-off between maximizing efficiency and keeping the inverter current rating and, hence, inverter cost under control. The inverter current rating has two aspects, its continuous current rating set by the largest of the generating current ratings at minimum and maximum speed, and its transient current rating for the motoring condition.

\section{E. Discussion of Saturation Effects}

The analysis in this paper has neglected magnetic saturation and assumed constant machine equivalent circuit parameters. In general, saturation will increase the required stator current beyond that predicted in Fig. 19 for high currents. As a result, the optimal value of back-emf chosen as part of the efficiency vs. stator current rating trade-off can be expected to increase.

It is interesting to note that some of the impact of magnet flux reductions on increased stator current amplitudes may be offset by cross-saturation effects. For Design A it has been experimentally demonstrated in [7] that the high magnet flux produces cross-saturation which significantly reduces the $q$ axis inductance compared to that when weaker magnets are used. Thus, by reducing magnet remanent flux the $q$-axis inductance will increase which will tend to reduce the required stator current. This effect may partially offset some of the stator current increase due to saturation.

\section{CONCLUSIONS}

This paper has examined how changing the remanent flux density and number of turns in an interior PM machine design can be used to trade-off high speed iron losses against lowspeed current rating for a wide field-weakening range application.
The concept of the interior PM machine parameter plane has been introduced. This is based on describing interior PM machine designs with three dimensionless parameters: normalised peak back-emf, normalised characteristic current, and saliency ratio. The peak back-emf is normalised against peak rated line voltage and the characteristic current is normalised against the natural current, which is the minimum current to meet the peak output power requirement with unity power-factor and $100 \%$ efficiency. The interior PM parameter plane consists of axes of the peak back-emf and characteristic current for a given saliency ratio. Each point on the plane corresponds to a different interior PM machine design.

The interior PM parameter plane was used firstly to explore the variation of the required stator current under motoring and generating conditions. Choosing the rated current equal to the characteristic and natural currents produces the lowest stator current rating but requires high values of peak back-emf (associated with high iron losses) and/or saliency ratio (difficult to achieve). It was found that a value of characteristic current just above the natural current is a good starting point.

The parameter plane was then used to examine the effect of changing the number of turns and magnet remanent flux density on the iron and copper losses for a particular machine geometry. It has been shown that the selection of the peak back-emf value is a trade-off between machine efficiency and inverter current rating. In addition, other factors such as design constraints on the back-emf amplitude at maximum speed may also play an important role in the design process [8], requiring a careful consideration of several competing factors in order to determine the best machine design.

\section{REFERENCES}

[1] R. Schiferl and T.A. Lipo, "Core loss in buried magnet permanent magnet synchronous motors," IEEE Transactions on Energy Conversion, vol. 4, no. 2, pp. 279-284, Jun. 1989.

[2] B. Stumberger, A. Hamler and B. Hribernik, "Analysis of iron loss in interior permanent magnet synchronous motor over a wide-speed range of constant output power operation," IEEE Transactions on Magnetics, vol. 36, no. 41, pp. 1846-1849, Jul. 2000.

[3] V. Zivotic-Kukolj, W.L. Soong and N. Ertugrul, "Iron Loss Reduction in an Interior PM Automotive Alternator," IEEE Transactions on Industry Applications, Vol. 42, Issue 6, Nov./Dec. 2006, pp. 1478 - 1486.

[4] S.H. Han, W.L. Soong and T.M. Jahns, "An Analytical Design Approach for Reducing Stator Iron Losses in Interior PM Synchronous Machines during Flux-Weakening Operation", in Rec of 2007 IEEE Industry Applications Society Annual Meeting, New Orleans, Sept. 2007.

[5] W.L. Soong, P.B. Reddy, A.M. El-Refaie, T.M. Jahns and N. Ertugrul, "Surface PM Machine Parameter Selection for Wide Field-Weakening Applications", in Rec. of 2007 IEEE Industry Applications Society Annual Meeting, New Orleans, Sept. 2007.

[6] E.C. Lovelace, "Optimization of a Magnetically Saturable Interior Permanent-Magnet Synchronous Machine Drive," Ph.D. Thesis, June 2000, Massachusetts Institute of Technology, MA, USA.

[7] W.L. Soong and N. Ertugrul, "Inverterless High Power Interior Permanent Magnet Automotive Alternator," IEEE Transactions on Industry Applications, Vol. 40, No. 4, July/Aug. 2004, pp. 1083-1091.

[8] S.H. Han, T.M. Jahns, M. Aydin, M.K. Guven, and W.L. Soong, "Impact of Maximum Back-EMF Limits on the Performance Characteristics of Interior Permanent Magnet Synchronous Machines," in Rec. of 2006 IEEE Industry Applications Society Annual Meeting, Vol. 4, Oct. 2006, pp. 1962 - 1969 